\title{
navers
}

Revista de Gestão e Tecnologia

\section{Sustentabilidade empresarial e a dimensão da exequibilidade}

\author{
Waldemar Pacheco Júnior, Márcia do Valle Pereira Loch, \\ Sérgio Luiz da Silva, Antônio Sérgio Coelho, Vera Lúcia \\ Duarte do Valle Pereira e Álvaro Guillermo Rojas Lezana
}

\section{RESUMO}

A sustentabilidade é um tema que tem evoluído conceitualmente, porém, em função da necessidade de adoção de abordagem sistêmica, também é um paradoxo quando se trata de realização de ações práticas nas empresas, uma vez que as áreas que a abrangem apresentam divergências para o alcance de diferentes objetivos. Sob a ótica empresarial, o paradigma de produção à geração de riqueza é preponderante e, assim, os referenciais de avaliação são direcionados para os resultados de seus sistemas produtivos. Neste aspecto, eficiência, eficácia e efetividade são dimensões que possibilitam gerar indicadores apropriados aos objetivos de produção, porém, normalmente não consideram as demandas das sociedades. 0 presente artigo evidencia conceitualmente tais aspectos diante da imposição das sociedades quanto ao alcance da sustentabilidade pelas empresas. Sugere, pois, o conceito de exequibilidade, uma dimensão teoricamente apropriada à avaliação dessas responsabilidades referidas a riscos dos impactos das ações. Dessa dimensão, emerge um conceito de desenvolvimento sustentável empresarial.

Palavras-Chave: Sustentabilidade. Desenvolvimento Sustentável. Exequibilidade.

\begin{abstract}
Although sustainability is a subject that has evolved conceptually, given the necessity for adopting a systemic approach, sustainability is also a paradox when it comes to realising practical actions within companies, since the diversity of areas involving it present different paths to achieving different objectives. Under a corporate point of view, the paradigm of production for generating wealth prevails, thus redirecting the evaluation criteria to the results of their production systems. Therefore, efficiency, efficacy, and effectiveness are dimensions that make possible to generate indicators that are appropriate to the production objectives. However, they normally do not take into account demands made by societies. This paper presents such aspects conceptually in relation to society's imposition regarding business sustainability. We here suggest the concept of feasibility, a dimension theoretically appropriate to the evaluation of such responsibilities when referring to the risks from the impact of actions. From that dimension emerges a concept of sustainable business development.
\end{abstract}

Keywords: Sustainability. Sustainable Development. Feasibility 


\section{INTRODUÇÃO}

Contemporaneamente, os produtos e, por implicação, os processos produtivos, ainda são tidos como essenciais à riqueza das sociedades, em razão de nossos modelos de desenvolvimento e do padrão tradicional de cálculo do crescimento econômico de uma nação, refletidos no Produto Interno Bruto (PIB) ou ainda no Produto Nacional Bruto (PNB). Muñoz (2008) é taxativo em dizer que o termo desenvolvimento é entendido como sinônimo de crescimento do produto nacional bruto. Em uma mesma perspectiva, Michelini e Razzoli (2003) se posicionam afirmando que a criação de riqueza na sociedade industrializada é até hoje ligada, em larga medida, ao incremento de consumos materiais pela atividade manufatureira que, a partir de material bruto, agrega "valor", permitindo a aquisição de benefícios à empresa.

Sem dúvida, os padrões de riqueza tradicionalmente utilizados envolvem o que se produz, e servem de referencial à atuação das organizações e às suas atividades produtivas, com variantes em relação à agregação de valor dos produtos às demandas de mercado. Em face de os modelos de produção se constituírem em consequências das estratégias produtivas adotadas, a Engenharia de Produção assume papel relevante, visto se constituir em elo entre os setores técnico e administrativo para geração de riqueza às empresas.

De acordo com Silva e Menezes (2001), a Engenharia de Produção é um ramo da engenharia que objetiva o estudo, o projeto e a gerência de sistemas integrados de pessoas, materiais, equipamentos e ambientes, visando à melhoria e garantia da produtividade do trabalho, a qualidade do produto e a saúde das pessoas em suas atividades laborais. Conceitualmente, a sua abordagem é interdisciplinar que engloba um conjunto de conhecimentos e habilidades não apenas da engenharia, mas também, de outras áreas científicas, notadamente das Ciências Sociais, propiciando o planejamento, a melhoria e a implementação sistêmica de produtos e processos produtivos, incluindo a organização do trabalho.

Nesse desígnio, as atividades dos sistemas produtivos de que trata a Engenharia de Produção são avaliadas em três dimensões, referindo-se a resultados, as quais se constituem em demandas internas das próprias organizações (GRAÇA, 2002; SANDER, 1995; BRASIL, 2004):

- Eficiência: habilidade de "fazer certas as coisas", na qual a organização se volta para "dentro", estrutura-se e se racionaliza, centrando sua preocupação técnica nos métodos, processos e normas de trabalho, com vistas a produzir "o máximo de resultados com o mínimo de recursos";

- Eficácia: capacidade de "fazer as coisas certas", na qual a organização se preocupa no gerenciamento com as metas em médio prazo através do trabalho organizado e racional, respeitando normas e processos bem definidos para garantir a execução de projetos, focando o alcance dos resultados produtivos propostos; e,

- Efetividade: capacidade de "acontecer hoje e amanhã", em que a organização vislumbra a gestão de perpetuidade, com visão nos resultados em longo prazo que possam garantir o futuro de execução dos seus projetos, com produtos e processos produtivos satisfazendo as demandas de 
mercado.

Pelo referencial de desenvolvimento, essas três dimensões também são balizadas pelo tangível, e, assim, as práticas de produção se voltam quase que única e exclusivamente aos processos que garantam produtos para o mercado, pois estes são os meios de obtenção de lucratividade e manutenção de estruturas ativas.

Constata-se, todavia, que nem sempre há preocupação com os impactos das práticas de produção em âmbitos para além da própria organização, exceto aqueles diretos que possam depreciar a imagem perante agentes do mercado ou em situações exigidas por normas legais e regulações. Isso já é observado em Clark (1998) quando discorre sobre as responsabilidades dos negócios para outros grupos de agentes, além dos proprietários. 0 tema também é presente no discussion paper - What do we really want? A manifesto for the organizations of the 21st Century (The MIT 21st Century Manifesto Working Group, da Sloan School of Management - Massachusetts Institute of Technology, 1999). Ambas as abordagens, elaboradas em distantes momentos do Século XX, questionam as formas de atuação das organizações, em que pesem suas capacidades técnicas e econômicas. Especialmente o Manifesto destaca que

em muitos casos, no entanto, estas organizações altamente eficientes não estão conseguindo o que nós seres humanos realmente quereremos. A atual organização da atividade econômica está intensificando a desigualdade econômica. Ela está erodindo os sistemas ambientais. E isso está gerando tensões insustentáveis sobre as pessoas, mesmo aquelas de

"sucesso" no sistema. Acreditamos que está mesmo se tornando cada vez mais disfuncional da perspectiva

\begin{abstract}
da eficácia econômica tradicional em um mundo em que a vantagem competitiva depende da geração de compartilhamento de conhecimento e gestão de interdependências cada vez mais complexos e de mudanças. (THE MIT 21st CENTURY MANIFESTO WORKING GROUP, 1999).
\end{abstract}

Grande peso na gestão das empresas incide, na atualidade, nos processos de expansão financeira que, com toda a sua carga especulativa, está gerando um grande peso contra a sustentabilidade, pois apesar de ter pouco a ver com a produção física, sobre seu domínio da econômica é tal que condicionam e definem a estrutura industrial. Mais ainda: está definido o perfil global da produção e consumo (MERCADO; CÓRDOVA, 2005).

Produção e finanças são elementos da economia e da gestão das empresas. A economia, por sua vez, ignora o conceito de entropia ${ }^{1}$ (FILIPPIN, 2007) e, por isso, no âmbito global há evidentes e manifestas contestações da medição de desempenho econômico baseado simplesmente na geração de produtos. Alega-se que não há ponderação quanto aos efeitos das atividades produtivas nas condições de vida da população, além de desconsiderar os índices relacionados ao potencial de riqueza dos recursos naturais. Tais contestações surgiram tímidas e isoladas, mas ganharam corpo nas duas últimas décadas do século $\mathrm{XX}$, sobretudo, após assinatura do Protocolo de Kyoto, em 1997. A partir desse evento fica evidente e público que os modelos de 10 conceito de entropia, proposto pelo prussiano Rudolf Emmanuel Clausius (1822-1888) para explicar o máximo de energia que poderia ser transformada em trabalho útil, está relacionado ao grau da ordem ou desordem em um sistema - quanto mais desordenado o sistema, maior será sua entropia (TSALLIS et al., 2000). Qualquer sistema isolado evolui fatalmente no sentido do estado de sua máxima entropia e, para subsistir, deve ser reabastecido da necessária energia para evitar a própria degradação, com resultantes no ambiente externo (TRONCONI et al., 1991). 
desenvolvimento adotados pelos diversos países podem ter relação direta com o aquecimento global, devido à emissão de gases poluentes precursores do efeito estufa à geração e consumo de energia. Dessa preocupação surgem debates em relação a outros fatores que principiam e/ou potencializam efeitos prejudiciais ao ambiente físico e, por extensão, às populações.

Para autores como Bauman (2008) e Baudrillard (1991), o consumo como modo de vida das sociedades contemporâneas também contribui de modo significativo para problemas dessa ordem, mas trata-se de uma resultante em que a arquitetura dos sistemas de produção se articula com as estratégias de marketing para alcançar a efetividade das organizações. Significa neste intuito, portanto, tão somente a transferência de responsabilidades, não condizente com as preocupações emergentes da sociedade, ou seja, de toda e qualquer forma degenerativa que os sistemas de produção impõem ao meio ambiente e às populações. É evidente que há uma inflexão clara da abordagem mecânica, simples e linear, predominantemente radicada no crescimento econômico, para uma abordagem dinâmica, complexa e transdisciplinar, centrada no Homem (COUTO et al., 2006).

As contestações do desempenho econômico global em relação ao que se considera a produção como único fator gerador de riqueza também alcança as organizações, na maioria das vezes, não explicitamente, mas através de impactos que margeiam e influenciam as dimensões de eficiência, eficácia e efetividade. Soubbotina (2004, p.8) destaca que a história oferece uma série de exemplos onde o crescimento econômico não foi acompanhado de progressos semelhantes no desenvolvimento humano. Em vez disso, o crescimento foi conseguido à custa de uma maior desigualdade, aumento do desemprego, a democracia enfraquecida, perda de identidade cultural, ou consumo excessivo de recursos naturais necessários para as gerações futuras. Como as ligações entre o crescimento econômico e as questões sociais e ambientais são melhor compreendidos, experts, incluindo os economistas tendem a concordar que este tipo de crescimento é insustentável, inevitavelmente, isto é, não pode continuar na mesma linha por muito tempo (tradução nossa).

A forma de utilização da mão de obra nos sistemas de produção, por exemplo, pode propiciar resultados privilegiando a qualidade dos produtos, porém, ocasionando outros impactos que normalmente são negligenciados ou, por prudência de imagem, escamoteados, mas ocasionando agravos de ordem física, fisiológica, emocional, psíquica, social e econômica aos trabalhadores. Esses danos apresentam repercussões múltiplas que não se limitam a impactar na própria organização, mas se estende para fora, com custos de toda ordem cada vez menos aceito pelas sociedades, não apenas na esfera econômica. 0 mesmo ocorre com outras formas de impacto, exigindo uma revisão e reestruturação na questão do desempenho econômico por parte das organizações.

Impera, pois, nesse contexto de necessidade de mudança de paradigma, tanto em nível global quanto local, o conceito de sustentabilidade. E a grande discussão em torno da sustentabilidade dirige-se à construção de indicadores - instrumentos que permitem mensurar as modificações nas características de um sistema - e que 
permitem avaliar a sustentabilidade dos diferentes sistemas (DEPONTI, 2002). Porém, às organizações, a discussão não pode estar limitada apenas às dimensões de eficiência, eficácia e efetividade, sob pena de incorrer em malogros de toda ordem. Isto porque há a necessidade elementar de entendimento das condições que geram os indicadores, o que Hronec (1993) define como "sinais vitais" das formas de atuação das organizações.

\section{SUSTENTABILIDADE E DESENVOLVIMENTO SUSTENTÁVEL: DESAFIOS ÀS ORGANIZAÇÕES}

A sustentabilidade tem como mola precursora o conceito de ecodesenvolvimento, referência microscópica de Maurice Strong ao modo criterioso, no qual, em áreas rurais de países do Terceiro Mundo, se utilizava os recursos naturais sem o esgotamento da natureza, evidenciando a coexistência dos vários fatores que possam compor um ecossistema (BRÜSEKE, 1994; LAYRARGUES, 1997). Posteriormente, Ignacy Sachs (1973 apud GODARD, 1991) deu maior impulso conceitual com o estabelecimento de três pilares que, de certo modo, solidificam as bases para o que atualmente se conhece por desenvolvimento sustentável: eficiência econômica, justiça social e prudência ambiental.

Esses pilares foram, nos últimos tempos, obtendo novas roupagens e reformulados em termos de responsabilidades, com o objetivo de chamar as organizações às incumbências que o mercado lhes impõe, inclusive sob o âmbito legal. Jaraben (2008), a partir de pesquisa na literatura, aponta para sete formas de discussão, o conceito de desenvolvimento sustentável:

- 0 conceito de paradoxo ético: trata das relações parodoxais entre sustentabilidade e desenvolvimernto (o direito a natureza versus dominação da natureza);

- 0 conceito de estoque de capital natural: examina o aspecto material do mundo teórico da sustentabilidade (manter o capital natural constante para benefícios das gerações futuras);

- 0 conceito de equidade: debate as capacidades de bem-estar; justiça social, ambiental e econômica;

- O conceito de ecoforma: explora as formas ecologicamente desejadas para os espaços urbanos e comunidades;

- O conceito de gestão integrativa: elabora uma visão holística e integrativa dos aspectos de desenvolvimento social, crescimento econômico e proteção ambiental;

- O conceito de utopia: transcende as preocupações ecológicas; preconiza uma sociedade perfeita (justiça, harmonia com a natureza, aloacação dos recursos);

- O conceito de agenda de política global: justifica uma política ambiental mundial a partir das ideias de sustentabilidade.

Observa-se, na literatura, a utilização de forma intercambiável dos termos "desenvolvimento sustentável" e "sustentabilidade". Na gestão dos negócios, a ideia de sustentabilidade possui implicações diversas. Hithcock e Willard (2006, p.8) salientam:

independentemente da definição, os que trabalham no campo da sustentabilidade em geral, todos encaram 


\begin{abstract}
a sustentabilidade como tendo três esferas: econômica, social e ambiental. Empresas há muito que se referem a isto como o "triple bottom line '. Em vez de negociar esses domínios uns contra os outros (empregos ou o meio ambiente, crescimento econômico ou saúde ambiental, desenvolvimento ou habitat), a sustentabilidade tem como objetivo otimizar os três (tradução nossa).
\end{abstract}

Percebe-se que, num primeiro momento, a ênfase recai na responsabilidade ambiental, com o intento de evitar o esgotamento dos recursos naturais, em caso de uso abusivo ou ameaçador pelos meios de produção. Depois disso, a preocupação passa à conjugação desse encargo com a responsabilidade social, uma vez que se percebe o homem como uma entidade social afetada pelos potenciais impactos que os meios de produção podem proporcionar direta e/ou indiretamente, não apenas no plano individual, mas especialmente na esfera coletiva. E, por fim, a preocupação é com a questão da responsabilidade econômica, não apenas visando obtê-la de forma isolada e voltada à lucratividade empresarial, mas respondendo adequadamente às demandas da sociedade que, em uma perspectiva ampla, requer a geração de benefícios nos fatores que a influenciam, direta ou indiretamente.

Neste aspecto, as responsabilidades são vistas sob diversas perspectivas, e nas organizações, num enfoque hierárquico, passam a ser preocupação em três níveis de ação:

- No nível institucional, o foco da efetividade deixa de ser apenas "os produtos absorvidos pelo mercado", mas "o que os produtos (e processos) resultam para o mercado" em termos dessas responsabilidades, o que exige um planejamento estratégico funcional de "fora para dentro" visando à efetividade;

- No âmbito tático, as respostas ao planejamento estratégico funcional demandam o incremento de planificação e controle dos sistemas de produção; envolvem, assim, a análise e a consideração de maior número de variáveis impostas por essas novas responsabilidades, impetrando mais exigências, inclusive sob forma de dispêndio de recursos, com afetação direta à eficácia empresarial; e,

- Na perspectiva operacional, as crescentes responsabilidades impõem incrementos de novas competências e habilidades no "saber fazer", com impacto na eficiência produtiva.

Os gestores se vêem, assim, em situação de maior complexidade, decorrente dessas responsabilidades que, se consideradas em relação às ações pontuais, espacial e temporalmente, são percebidas mais como incompatibilidades do que em oportunidades, em especial, nas ações necessárias à aplicação do conceito da sustentabilidade. As tomadas de decisão, em caso de percepção de incompatibilidades, em geral, são de negação parcial ou total à sustentabilidade, focando tão somente o objetivo da lucratividade, a qual pode ser "travestida" de distribuição de dividendos para os acionistas e participação nos lucros aos trabalhadores. Carrol e Buchholtz (2003) destacam: trata-se de ações de responsabilidade econômica. A justificativa para tal postura é de que há geração de riqueza, porém, esquecendo que muitas das ações podem estar esgotando a capacidade 
futura de geração de riquezas (inclusive a própria) e, o que é pior, promovendo pobreza ambiental e social, de forma direta ou indireta.

Os exemplos de situações de degradação dos diversos ambientes são inúmeros, dentre os quais se encontram os casos de utilização de madeira de florestas nativas que, num primeiro momento, geram riqueza (lucros). Porém, temporalmente, promovem uma série de impactos negativos que, se não forem adotadas medidas mitigadoras prévias, provavelmente comprometerão a disponibilidade do capital natural, com consequências ambientais e sociais nefastas.

Hithcock e Willard (2006) revelam que, para a gestão dos negócios, a adoção do conceito de sustentabilidade pelas organizações pode resultar em situações benéficas, ameaças e, ainda, riscos. Os benefícios podem ser identificados na redução de gastos com energia, perdas e custos; diferenciação dos competidores; abertura de novos mercados; melhoria da imagem em relação aos acionistas, investidores e comunidades; atração e retenção de talentos. As ameaças em não buscar uma condição de sustentabilidade estão presentes nos problemas com as fontes de matéria-prima e energia; nos ataques a imagem; nos riscos legais; nas críticas severas aos produtos; na exclusão de mercados. Os riscos, por sua vez, resultam da possibilidade de despertar expectativas irrealistas; canibalizar o próprio negócio, entre outras situações.

Numa perspectiva conceitual, a sustentabilidade sugere a capacidade holística de se interagir com os ambientes sem comprometê-los, portanto, podendo ser entendido como um contexto em que se caracteriza a coexistência benéfica entre sistemas. Com efeito, a partir de Von Bertalanffy (2008), pode-se dizer que os sistemas isolados não existem de e por si próprios, pois à consecução de seus processos visando atingir determinados objetivos, outras condições essenciais são necessárias: alimentação do processo, transformação, destinação dos produtos e mecanismo de regulação do processo. 0 sistema corpo humano, por exemplo, para gerar vigor (trabalho), tem um complexo processo metabólico em que necessita de adequada ingestão de nutrientes (alimentação); estes nutrientes são absorvidos e transformados pelo organismo (processo) em energia e outras resultantes (produtos); o metabolismo é regulado por engenhos homeostáticos à estabilidade funcional do processo (mecanismos de regulação), buscando o equilíbrio corporal com o seu meio externo.

Pode-se aferir que essa dinâmica também ocorre a todo e qualquer sistema produtivo estável, significando que à existência deve haver interação e interdependência a outros ou, em outras palavras, o intercâmbio com o seu meio, um fato não muito bem percebido pelas organizações. Embora impreciso (RATTNER, 1999) e sujeito a interpretações variadas (RUSCHEINSKY, 2003), o conceito de sustentabilidade induz para uma abordagem sistêmica e, como tal, exige que uma organização opere do (sofrendo influência) e para (influenciando) os meios em que se encontra, visando múltiplos benefícios mútuos.

Contudo, às organizações, o referencial dos modelos de desempenho econômico induz a operar para o meio, através daquilo que se produz objetivamente, com visão 
no impacto interno da lucratividade, conduta inconsistente com o conceito de sustentabilidade, pelo fato de não considerar outras demandas das sociedades - além dos produtos e seus benefícios. É evidente que a equação se torna imprecisa, urgindo que se aplique o conceito de desenvolvimento sustentável $^{2}$ aos sistemas de produção, uma vez que o desenvolvimento sustentável tem o intento de equilibrar e integrar três pilares fundamentais: a proteção do meio ambiente, o crescimento econômico e o bem-estar social (SANCHEZ ROSE; VESSURI, 2008).

Diante das dificuldades de obter-se o equilíbrio desses pilares fundamentais, nota-se existir um impasse na aplicação dos conceitos de sustentabilidade e desenvolvimento sustentável na gestão das organizações. Isto porque ainda não há um referencial de avaliação disseminado em que se inclua as diversas demandas da sociedade, explícitas e implícitas, presentes e futuras, com as quais aquelas possam planificar as suas estratégias de ação. Estratégias essas que deveriam envolver as responsabilidades ambientais, sociais e econômicas no âmbito das práticas da sustentabilidade.

\section{EXEQUIBILIDADE: UMA DIMENSÃO DIRECIONADA AO DESENVOLVIMENTO SUSTENTÁVEL}

0 conceito de desenvolvimento sustentável, em sua pura essência, vislumbra o alcance de resultados com a condicionante de não compremeter as necessidades de

\footnotetext{
2 Segundo a Comissão Mundial sobre Meio Ambiente e Desenvolvimento (CMMAD), da Organização das Nações Unidas (ONU), o desenvolvimento sustentável é um conjunto de processos e atitudes que atende às necessidades presentes sem comprometer a possibilidade de que as gerações futuras satisfaçam as suas próprias necessidades. [...] sustainable development is development that meets the needs of the present without compromising the ability of future generations to meet their own needs (WCED, 1987).
}

gerações futuras. Opera-se, destarte, com incertezas nas ações projetadas, ou seja, com a existência de riscos em uma perspectiva temporal. E são os riscos quanto ao não atendimento das responsabilidades sociais, ambientais e econômicas, que derivam de demandas da sociedade, os quais deveriam orientar a atuação das organizações, visando a própria estruturação estratégica de suas atividades, incluindo os seus processos de produção.

Segundo Bernstein (1997), risco deriva do antigo italiano risicare, com significado de ousar, dando a entender que se trata de alternativas de um evento depois de avaliados os seus possíveis efeitos. Isto remete à questão de existir diferentes resultados possíveis para um mesmo evento e, assim, risco se refere à probabilidade de potenciais efeitos. Ora, um evento e seus efeitos somente ocorrem devido à existência de variantes e, portanto, podem ocorrer muitas possibilidades em razão dessas variantes. Torna-se controvertido afirmar que a presença de um ou mais agentes poderiam proporcionar resultados fora do que se espera, exceto, é claro, se o contexto for favorável pela convergência de fatores. A presença de um produto tóxico à saúde humana num ambiente, por exemplo, é um perigo pelo fato de poder causar algum dano às pessoas. Pode não ocorrer malefícios, todavia, por diversos fatores: o produto estar apropriadamente armazenado ou as pessoas devidamente protegidas, por exemplo. É lícito afirmar, então, ser a conjunção de fatores ambientais que propiciam a materialização de um evento com seus possíveis efeitos, inclusive, diferentes do esperado. Assim, para referir-se a risco, é imperativo realizar-se a avaliação das 
possíveis situações, para fins de tomada de decisão, no sentido de interpretar os diferentes resultados das prováveis condições de ocorrência dos eventos.

Um efeito de um evento é tecnicamente denominado de impacto (do latim impactu, particípio passado de impingere, com significado de pôr à força; ir de encontro a), em vista de haver diferentes possibilidades de resultados, diretos ou indiretos, de um ou mais elementos do contexto. 0 conceito de impacto é de extrema importância ao se referir a um risco, pois indica a possibilidade de afetação no contexto. Portanto, como um impacto em um dado contexto pode ocorrer de forma direta ou indireta, bem como afetar o contexto de forma positiva, negativa ou mesmo neutra, pode-se classificar os riscos associando-os com estas possibilidades, em termos de categoria e tipificação:

- Categoria: diz respeito à forma de afetação sobre o objeto de análise, podendo ser:

- Direto: afetando-o primariamente; e/ou,

- Indireto: afetando-o secundariamente ou numa enésima ordem.

- Tipificação: reflete a qualidade de afetação sobre o objeto de análise, podendo ser:

- Positivo: gerando benefícios sobre o objeto, ou seja, alterando a sua funcionalidade com ganhos acima do esperado; ou,

- Neutro: não gerando benefícios e nem causando danos, o que significa manter a funcionalidade do objeto de avaliação de acordo com o esperado, ainda que haja alteração do evento; ou,

- Negativo: gerando danos ao fator em análise, ou seja, alterando a funcionalidade do objeto de avaliação com perdas.
Para determinar um risco, pelo próprio conceito, não basta tão somente identificálo em função do objetivo de análise; tampouco importa apenas classificar os presumíveis efeitos (diretos e/ou indiretos; positivos, negativos ou neutros). É necessário, pois, após essa identificação, expressar a possibilidade de o evento resultar nos efeitos possíveis para, a partir dessa, realizar a devida interpretação dos plausíveis impactos segundo o objetivo proposto. Uma vez que, em termos técnicos, a possibilidade tem relação com probabilidade, esta deve ser devidamente explicitada ou, pelo menos, estimada. Em termos matemáticos, a probabilidade simples é obtida pelo quociente entre a frequência de um determinado resultado pelo total de resultados possíveis ou, em caso de não se ter uma precisão, é viável a sua estimação, para que se possa ter apoio à interpretação dos impactos possíveis de um evento num dado contexto. Com base nessas considerações, pode-se afirmar que um risco somente pode ser caracterizado se houver três etapas de ação numa análise de determinada situação, a partir de um objetivo estabelecido:

a) Qualitativa, na qual se identifica os fatores ou agentes em suas interações e inter-relações com outros, bem como as possíveis consequências (impactos diretos e indiretos) no contexto em análise;

b) Quantitativa, na qual se afere a probabilidade ou estimativa das consequências de um evento visualizadas na etapa qualitativa, as quais são derivadas das interações e inter-relações dos fatores ou agentes do contexto considerado; e, 
c) Interpretativa, na qual se faz a análise das possibilidades dessas consequências e respectivas repercussões no referido contexto, considerando-se as ações qualitativas e quantitativas, conforme os propósitos preestabelecidos.

Estas três etapas da avaliação que descrevem e caracterizam um risco têm relação direta com a possibilidade de materialização de possíveis resultados de um evento, devido a condições em que os fatores envolvidos convirjam às suas ocorrências, ainda que com baixa possibilidade. Sem essas etapas, o risco somente seria aventado, uma condição tecnicamente inaceitável. Com efeito, há de se ponderar que todo e qualquer evento é originado de causas definidas e, devido às interações e inter-relações dos elementos que o compõem numa dada situação, acabam por consentir a previsão dos possíveis resultados do contexto. Se as causas que levam ao evento são bem conhecidas ou ao menos previstas, torna-se evidente visualizar as possibilidades dos respectivos efeitos. Então, também os riscos podem ser analisados, considerando-se que estes são referidos aos possíveis resultados de um evento num dado contexto e, ainda, inclusive, prevendo-se serem esses diretos e/ou indiretos, positivos, negativos ou mesmo neutros, o que depende do objetivo da avaliação.

Como todo impacto é, em termos técnicos, originado pela sequência da cadeia "causas-evento-efeitos" para uma determinada conjuntura espacial e temporal, os elementos dessa cadeia devem ser devidamente explicitados, para fins de entendimento da lógica funcional que retrata o fenômeno. Uma vez descritos tais elementos de lógica funcional e, em havendo uma grandeza que expresse a possibilidade de um evento produzir potenciais impactos, é que se pode interpretar o fenômeno e definitivamente caracterizar os riscos inerentes a ele.

Entretanto, uma vez que o Universo é dinâmico, é de prever-se que toda e qualquer cadeia de "causas-evento-efeitos" possa sofrer - e invariavelmente sofre interferências internas e externas em seus elementos, isolada ou conjuntamente, à sua funcionalidade (figura 1). As interferências internas são derivadas da alteração das condições funcionais dos elementos da cadeia e, as externas, em função de outros fatores que interferem nessas condições funcionais. Estas influências, propositais ou não, não previstas (ou negligenciadoas), oportunizam resultados diferentes do

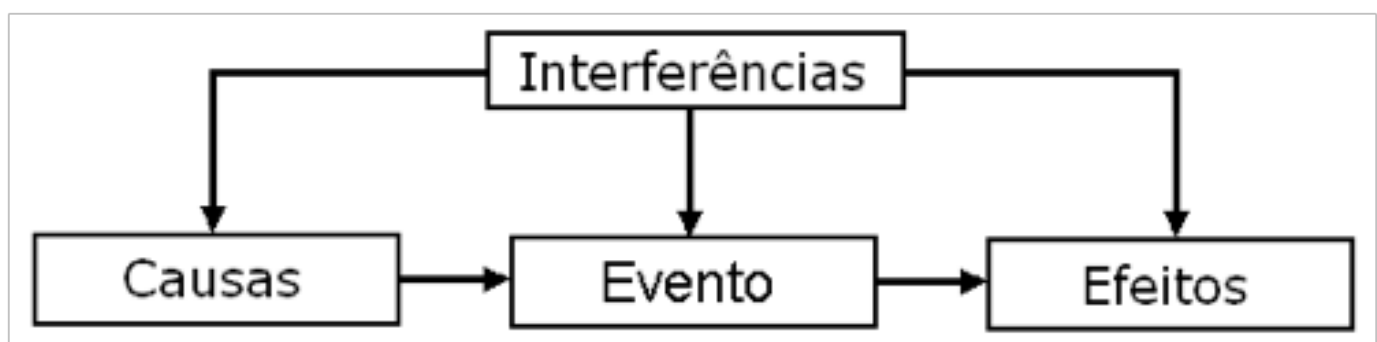

Figura 1- Cadeia de "causas-evento-efeitos" retratando um fenômeno Fonte: Dos autores 


\section{Ambiente}

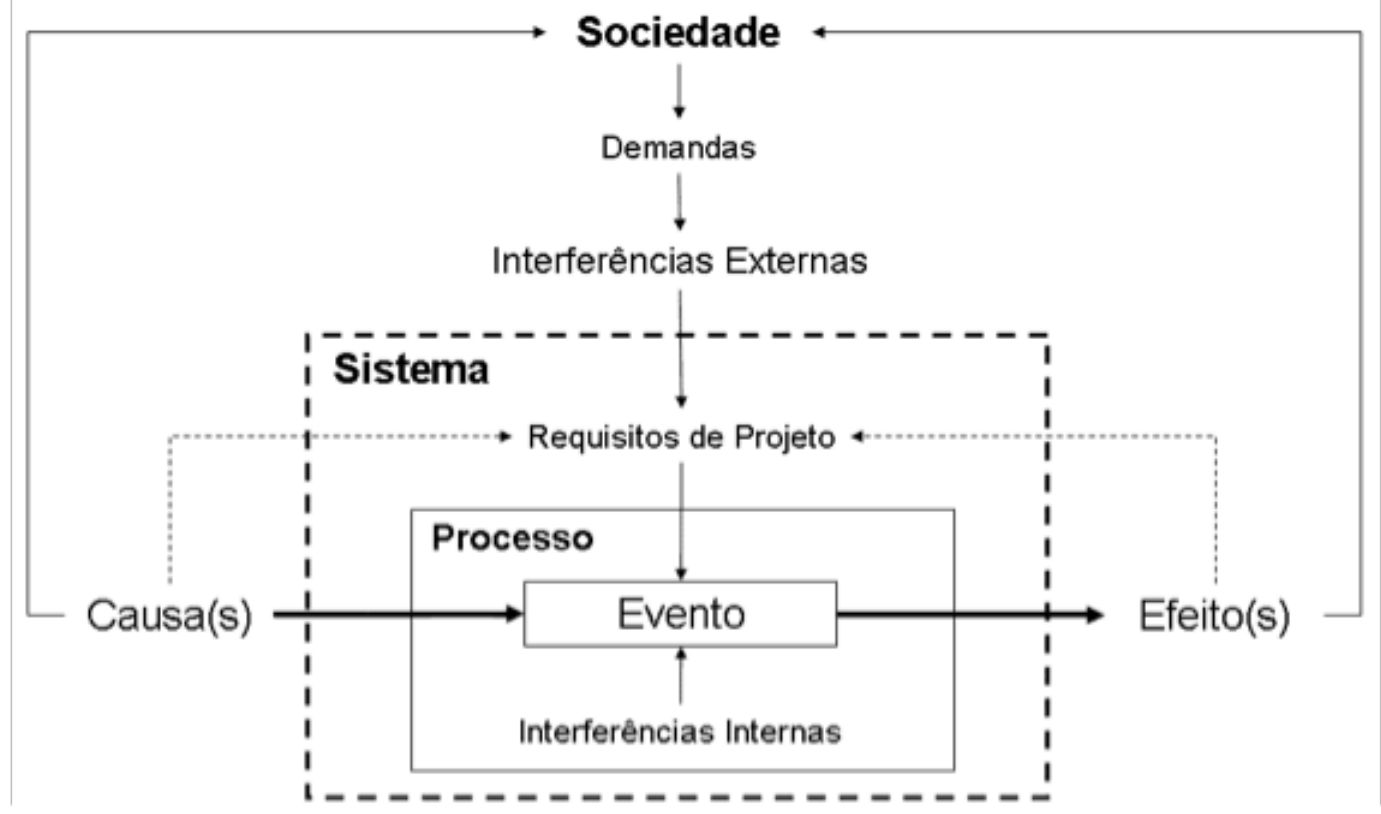

Figura 2 - Representação das demandas sociais interferindo nos requisitos de projetos na cadeia de "causas-evento-efeitos" de um sistema. Fonte: Dos autores

esperado, em razão de modificação das características funcionais dos elementos dessa cadeia.

Admitindo-se haver interferências externas, o que ocorre nas demandas das sociedades em relação à sustentabilidade, pode-se pressupor que a estrutura funcional de toda e qualquer cadeia de "causasevento-efeitos" seja um sistema aberto. Então, o risco de um potencial impacto, que somente é caracterizado quando apropriadamente qualificado, quantificado e interpretado, deve ser tratado em uma abordagem sistêmica, considerando possíveis interferências. Nessa perspectiva sistêmica, as demandas das sociedades são interferências externas aos sistemas produtivos, as quais estão se constituindo em requisitos de projeto dos processos produtivos em toda a cadeia de "causas- evento-efeitos", conforme a figura 2, que intenta mostrar as interações gerais.

Ao assumir as responsabilidades sociais, ambientais e econômicas para adequação dos seus sistemas de produção ao conceito da sustentabilidade, as organizações deveriam considerar as interferências em seus processos quanto às demandas explícitas e implícitas das sociedades em suas ações, presentes e futuras. Então, seria prudente incluir a análise de riscos dos impactos existentes e emergentes dos seus produtos e processos produtivos quanto ao não atendimento dessas demandas. Isso sugere observar outra dimensão de avaliação dos resultados, somada às de eficiência, eficácia e efetividade. Tratase de uma dimensão em que se analisa a possibilidade de produtos e processos produtivos atenderem às demandas da 
sociedade. Propõe-se, neste aspecto, a terminologia de exequibilidade. Com efeito, exequível significa algo que pode ser executado ou cumprido, exprimindo que pode ser percorrido, sem obstáculos; denota um caráter de possibilidade e, assim, traduzse numa dimensão temporal, não se atendo apenas ao momento atual.

Na impossibilidade de atendimento das demandas da sociedade, há entraves que devem ser superados, inclusive no âmbito temporal. Portanto, a dimensão da exequibilidade poderia de constituir em referência às estratégias (e avaliações) organizacionais de adequação de produtos e processos produtivos na questão do desenvolvimento sustentável.

Com efeito, a dimensão da exequibilidade diz respeito à capacidade e habilidade de uma organização em atender às demandas explícitas e implícitas das sociedades, mostrando serem os seus resultados convergentes ao conceito de desenvolvimento sustentável. Trata-se de ações produzidas pela organização que resultem e/ou possam resultar em benefícios sistêmicos, o que requer antecipação em relação aos riscos de possíveis impactos de seus produtos e processos às sociedades nas quais tem influência direta e/ou indireta. Tais benefícios, evidente, uma vez que se trata de sustentabilidade, são das esferas ambiental, social e econômica, e com as quais uma organização deve se situar perante as sociedades para atender aos seus requisitos, temporais e espaciais.

\section{CONSIDERAÇÕES FINAIS}

É natural que, ante um referencial determinístico de desenvolvimento, as organizações tenham dificuldades de propor e implementar projetos de ação que viabilizem o desenvolvimento sustentável em suas atividades. Isso se torna mais crítico quando há a necessidade sistêmica de obtenção de benefícios, sobretudo, quando se considera as demandas explícitas e implícitas das sociedades. A exiquibilidade sugere que, para o alcance da sustentabilidade, se deva adotar um novo referencial de orientação, para fins de que as ações possam ser benéficas e viáveis em termos econômicos, ambientais e sociais.

A posição é, portanto, no momento, essencialmente conceitual e envolve áreas distintas no âmbito da sustentabilidade, com objetivos não necessariamente convergentes devido a problemas diferenciados no que se refere ao desenvolvimento sustentável. Pressupõe-se, assim, a necessidade de conhecimento transdisciplinar que, segundo Nicolescu (1997), pela sua natureza é integrador e apropriado para tomadas de decisão quanto à solução de problemas complexos, que é o caso das atuais demandas das sociedades.

Na perspectiva organizacional, a dimensão de exiquibilidade pode potencializar a construção de indicadores de seu desenvolvimento sustentável. Porém, o conhecimento transdisciplinar seria, em hipótese, a base à construção dos próprios indicadores e, neste sentido, fóruns de stakeholders, endógenos e exógenos, nas diversas esferas de ação de empreendimentos (estratégico, tático e operativo) (DUARTE, 2008), seriam essenciais. Permitiria, assim, a identificação e antecipação das causas, dos eventos e dos impactos dos processos produtivos e 
produtos quanto às demandas mediatas e imediatas das sociedades, considerando-se os riscos sistêmicos dos projetos. Produz-se possivelmente, deste modo, um processo sistêmico de estruturação funcional das atividades de uma empresa visando a exequibilidade social, ambiental e econômica dos recursos/ processos/produtos no seu âmbito de atuação, ou seja, do próprio desenvolvimento sustentável empresarial.

\section{REFERÊNCIAS}

BAUDRILLARD, J. A sociedade de consumo. Lisboa: Edições 70, 1991.

BAUMAN, Zygmunt. Vida para consumo. São Paulo: Zahar, 2008.

BERNSTEIN, P. L. Desafio aos deuses: a fascinante história do risco. 6. ed. Rio de Janeiro: Campus, 1997.

BERTALANFFY, L. von. Teoria geral dos sistemas: fundamentos, desenvolvimento e aplicações. 3. ed. Rio de Janeiro: Vozes, 2008.

BRUSEKE, F. J. 0 Problema do Desenvolvimento Sustentável. In: BRASIL. Ministério da Educação.

Desenvolvimento e Natureza: Estudos para uma sociedade sustentável. Recife, Octubre. 1994. p. 262. Disponível em: http://168.96.200.17/ar/ libros/brasil/pesqui/cavalcanti.rtf. Acesso em: 8 set. 2011.

CARROL, A. B.; BUCHHOLTZ, A K. Business \& society: ethics and stakeholder management. 5. ed. Mason: ThomsonSouth-Western, 2003.

CLARK, J. M. The changing basis of economic responsability. In: CLARKSON, Max B. E. The corporation and its stakeholders: classic and contemporary readings. Toronto: University of Toronto Press, 1998.

COUTO, A. P.; ALVES, M. C.; CARVALHO, P. G. de; MATOS, A. F. de. Universidade e Trandisciplinaridade na Transição para a Sustentabilidade: Uma análise exploratória. 2006. Disponível em: <http://thesis.ubi.pt/ upload//679/universidadeetrandis.pdf>. Acessado em 10 ago. 2009.

DEPONTI, C.M.; ECKERT, C.; AZAMBUJA, J. L. B. Estratégia para construção de indicadores para avaliação da sustentabilidade e monitoramento de sistemas. Agroecol. e Desenvol. Rur. Sustent. Porto Alegre, v. 3, n. 4, out/ dez 2002. Disponível em: http://www.pronaf.gov.br/dater/arquivos/0758809505.pdf. Acesso em: 07 ago. 2009.

DUARTE, P. M. Avaliação de uma Empresa não Cotada no Sector da Distribuição Cinematográfica (Estudo de Caso). Lisboa: ISCTE, 2008. Disponível em: <http://hdl.handle.net/10071/637>. Acesso em: 04 ago. 2009.

FILIPPIN, Rafael Ferreira. A decisão de aproveitar o Rio Tibagi para a geração de Energia Elétrica: aspectos políticos, ambientais, econômicos e jurídicos. Dissertação (Mestrado em Direito) - Universidade Federal de Santa Catarina, Florianópolis, 2007.

GRAÇA, Hélio. É preciso pensar no futuro agora? FUNADESP. Seminário Gestão de IES: da Teoria à Prática. Disponível em: <www.funadesp.org.br/Publica/Anais/sergio_fiuza.pdf>. Acesso em: 29 ago. 2002.

GODARD, O. Environnement Soutenabie et DéveloppementDurable: Le modèle néo-classique en question. Paris: Environnementet societé 91- CIRED, 1991.

LAYRARGUES, P. P. Do Ecodesenvolvimento ao Desenvolvimento Sustentável. Revista Proposta. Rio de Janeiro: FASE, 1997. Disponível em: <http://material.nerea-investiga.org/publicacoes/user_35/FICH_ES_32.pdf>. Acesso em 11 jul. 2011.

MUNOZ, R. V. Carrión. Ingeniería Industrial y Desarrollo. Revista de la Facultad de Ingeniería Industrial. V.11, n.1, p. 14-20, 2008. Disponível em: <http://www.scielo.org.pe/pdf/id/v11n1/a03v11n1.pdf>. Acesso em: 03 ago. 2009.

NICOLESCU, Basarab, The transdisciplinary evolution of the university condition for sustainable development: Presented at the 'Universities' Responsibilities to Society', Bangkok: Chulalongkorn University. Disponível em: <http://basarab.nicolescu. perso.sfr.fr/ciret/bulletin/b12/b12c8.htm>. Acesso em: 10 ago. 2009.

RATTNER, H. Sustentabilidade: uma visão humanista. Ambiente \& Sociedade v. 2, n. 5, 2. Sem. 1999. Disponível em: <http://www.scielo.br/pdf/asoc/n5/n5a20.pdf>. Acesso em: 19 jul. 2011. 
RUSCHEINSKY, A. No Conflito das Interpretações: 0 Enredo da Sustentabilidade. Revista Eletrônica do Mestrado em Educação Ambiental. v. 10, jan./jun. 2003. Disponível em: <http://www.remea.furg.br/mea/remea/ vol10/art4.pdf>. Acesso em: 23 jun. 2011.

SACHS, I. Población, Tecnología, Recursos Naturales y Medio Ambiente. Boletín Económico de América Latina, V. $18,1973$.

SANDER, B. Gestão da educação na América Latina: construção e reconstrução do conhecimento. Campinas: Autores Associados, 1995.

SOUBBOTINA, T. P. Beyond economic growth: An introduction to sustainable development. Washington (DC): The World Bank, 2004.

TRONCONI, P. A.; VALOTA, R.; AGOSTINELLI, M.; RAMPI, F. Pianeta in préstito: energia, entropia, economia. Preggio: Macroedizioni, 1991.

TSALLIS, C.; MAGALHÃES, A. C. N.; CURADO, E. M. F. Uma nova entropia. Grupo de Mecânica Estatística - Física Estatística. Revista do CBPF. Rio de Janeiro: Centro Brasileiro de Pesquisas Físicas, 2000. Disponível em: <http:// portal.cbpf.br/protected/Pages/divulgacao/pdfs/FisEstatist.pdf>. Acesso em: 22 jun. 2011

WCED. Our Common Future. World Commission on Environment and Development, Oxford, Oxford University Press, 1987.

\section{Waldemar Pacheco Júnior}

Pós-Doutorando em Engenharia de Produção

Departamento de Engenharia de Produção e Sistemas - UFSC

Programa Nacional de Pós Doutorado - PNPD

Correio eletrônico: pjr.w@hotmail.com

Currículo Lattes: http://buscatextual.cnpq.br/buscatextual/visualizacv.do?id=K4790211D0

\section{Márcia do Valle Pereira Loch}

Pós-Doutoranda em Engenharia de Produção

Departamento de Engenharia de Produção e Sistemas - UFSC

Programa Nacional de Pós Doutorado - PNPD

Correio eletrônico: marcia.loch@hotmail.com

Currículo Lattes: http://buscatextual.cnpq.br/buscatextual/visualizacv.do?id=K4736000A8

\section{Sérgio Luiz da Silva}

Pós-Doutorando em Engenharia de Produção

Departamento de Engenharia de Produção e Sistemas - UFSC

Correio eletrônico: sergio@prof.sc.senac.br

Currículo Lattes: http://buscatextual.cnpq.br/buscatextual/visualizacv.do?id=K4770046P8

\section{Antônio Sérgio Coelho}

Departamento de Engenharia de Produção e Sistemas - UFSC

Correio eletrônico: coelho@deps.ufsc.br

Currículo Lattes: http://buscatextual.cnpq.br/buscatextual/visualizacv.do?id=K4783891H7 


\section{Vera Lúcia Duarte do Valle Pereira}

Departamento de Engenharia de Produção e Sistemas - UFSC

Correio eletrônico: vpereira@deps.ufsc.br

Currículo Lattes: http://buscatextual.cnpq.br/buscatextual/visualizacv.do?id=K4781588J6

\section{Álvaro Guillermo Rojas Lezana}

Departamento de Engenharia de Produção e Sistemas - UFSC

Correio eletrônico: lezana@deps.ufsc.br

Currículo Lattes: http://buscatextual.cnpq.br/buscatextual/visualizacv.do?id=K478038 
Waldemar Pacheco Júnior, Márcia do Valle Pereira Loch, Sérgio Luiz da Silva, Antônio Sérgio Coelho, Vera Lúcia Duarte do Valle Pereira e Álvaro Guillermo Rojas Lezana 